\title{
A MEASUREMENT MODEL OF TALENT MANAGEMENT PRACTICES AMONG UNIVERSITY STAFF IN CENTRAL REGION OF UGANDA
}

\section{Miiro Farooq ${ }^{\mathrm{a}}$, Azam Othman ${ }^{\mathrm{b}}$, Mohamad Sahari Nordin ${ }^{\mathrm{c}}$, Mohd Burhan Ibrahim ${ }^{\mathrm{d}}$}

\author{
${ }^{a}$ International Islamic University Malaysia, Kuala Lupur, Malaysia \\ Staff Islamic University in Uganda, Mbale, Uganda \\ b,c,d International Islamic University Malaysia, \\ Faculty of Education, Kuala Lupur, Malaysia \\ a e-mail: miirofarooq@gmail.com \\ b e-mail: azam_othman@iium.edu.my \\ ce-mail: msahari@iium.edu.my \\ de-mail: mburhan@iium.edu.my
}

\begin{abstract}
The empirical study objective was twofold; first to survey the degree to which university staff perceive on the use of talent management instituted a meaningful practice at universities of central region in Uganda; secondly it focused on testing the suitability of the dimension in terms of reliability, convergent validity, discriminant validity; and measurement equivalence for both working experience, and gender of university staff. The sample covered 808 university staff from six universities in the Central Region of Uganda in the year 2016. Data collection was done using a self-reported 24-item questionnaire so as to determine how the university staff perceive the construct of talent management practices. The Survey tool was distributed by the researcher and researcher assistants to volunteers in the six universities that participated in this study. The outcomes of the study reinforced, illuminated and gave a deeper insight into the results of previous studies on the same subject which has been infused in the university business and strategy. The study furthermore found evidence of validity and reliability for a multidimensional construct of talent management practices. Also, the measurement for working experience proved variant whereas gender was invariant. The findings of the study will be help stakeholders to contrive informed suggestions towards decision making for developing and retaining university staff to towards university effective performance, and is a source of information and knowledge to future research in the same area.
\end{abstract}

Keywords: Talent management practices, University effectiveness and performance, confirmatory factor analysis

Paper type: Research paper 
A MEASUREMENT

MODEL

OF TALENT

Miiro Farooq

Azam Othman

Mohamad Sahari Nordin

Mohd Burhan Ibrahim

\section{Introduction}

Since the inception of the war on talent in 1998, many large organizations both in business and academic sectors initiated talent management practices as a remedy for today's labour market competition (Collings, 2014; Bethke-Langenegger et al., 2011). Talent management practices are intended to help organizations attract, develop and retain talented employees (Mary et al., 2015). The goal of talent management practices is to develop potential employees to successfully improve organization's effectiveness and performance for today and tomorrow so as to be present in the world stage (Barkhuizen et al., 2014; Zurich, 2012).

\subsection{The nature of Universities Practice towards talent management}

With the globalisation tendencies and the post-modern knowledge economy influences that are converting the world into one merged pillage, human life is made to be more unstable and unpredictable, to the extent that, every moment in the new day the world experiences new dimensions and forces that call for rapidity in changing human resource management style from the usual outmoded method to organisational elites (The University of Scranton Planning Office, 2009; Commission et al., 2011; Cipd, 2008; Barkhuizen et al., 2014; Commission et al., 2011; Iqbal et al., 2013). The forces seen above, with un clear defined direction, appear in human life and create uncertainties even at work place, and this is normally coupled with turbulent moments whose indistinct ways lead the society into unprecedented episodes for instance, climate changes health hiccups, conflicts, climate change and water shortages etc. (Knight, 2012; Mary et al., 2015; Deloitte, 2016; Heis, 2014; Montanini, 2013). Moreover, such challenges do not only affect institutional stability but also influence workers' movements for better chances and job security. Yet, it is empirically clear that through trained human resources, organisations can thrive amid these challenges and improve performance to better their position in the world market stage (Mary et al., 2015; Mayer et al., 2014; Montanini, 2013; Gakure, 2013; Richards, 2012; Rudhumbu, 2014).

Subsequently, educational excellence is the key to world class branding today, as it is the main source of marketable and suitable academic programmes that can facilitate the attraction and retention of foreign and local students (Barkhuizen et al., 2014; Annakis et al., 2014). It is therefore the onus of university leadership to facilitate talented staff to stay in their institutions and at the same time increase staff's capabilities so as to produce graduates that will meet the requirements of the global market. Nonetheless, some universities are lagging behind in this aspect and incapacitated in regard to producing the needed human resources to facilitate the needs of the industries in the field (Annakis et al., 2014). 


\subsection{Talent Management}

Talent management is a phenomenon with ambiguous definitions due to lack of a theoretical framework to govern its spectrum (Campbell and Hirsh, 2013; Ariss, 2014; Aljunaibi, 2014; Sirkova et al., 2015). However, the study will use recent definitions to provide a conceptual framework. For instance, Talent management is viewed as the strategy of identifying gaps in influential institutions' positions with an aim of recruiting, selection, and development of suitable staff and motivate them to stay for succession planning initiatives (BethkeLangenegger et al., 2011; Bauer and Greven, 2015; Nijveld, 2014; Keçecioğlu et al., 2014). It is also a crucial factor through which individuals can brand organisational performance, either by short or long term contribution and also demonstrate the uppermost levels of potential performance (Cannon and McGee, 2011; Maphota, 2016; Stanley, 2006). Furthermore, talent management normally targets the future sustainability of institutions existence and excellence (Annakis et al., 2014; Devins and Gold, 2014; Bethke-Langenegger et al., 2011; Hariss and Foster, 2010). Thus, it is important for an institution to focus on someone's credibility, skills and competence that can enhance change through provision of quality services provided to the customers (Collings, 2014; Ariss, 2014; Cannon and McGee, 2011). Additionally, It may also imply a collective value of worker coupled with the institutional strategic success (Devins and Gold, 2014; Nijveld, 2014; Sarangi, 2013). In line with the above, development of human resources' skills, expertise, knowledge and experiences is envisaged as a motivation factor towards employees' better performance (Sirkova et al., 2015; Vnoučková, 2016). In other words, it is an imperative towards employee motivation and change of their behaviour towards institutional future quality services (Tansley et al., 2013; Moayedi and Vaseghi, 2016; Aljunaibi, 2014).

In the context of the study, talent management denotes to the procedure through which highly skilled new and old workers are attracted, developed, retained and integrated into the institution's system, for purposes of improving institutional performance on the global market (Annakis et al., 2014; Barkhuizen et al., 2014). Since universities are governed by highly qualified staff in terms of academic qualifications, knowledge and skills, talent management in this case can be referred to as continuous provision of training grounds and means through which the highly performing staff can be developed to meet the potential new jobs and roles after fulfilling the knowledge gaps, and implement initiatives for enrichment of the competencies among academicians in the university. It is therefore the work of heads of departments, Deans and Human Resources Managers to always remind the staff both the academic and administrative about the new and existing opportunities for acquisition of adequate training and professional development (Heis, 2014; Richards, 2012; Strategic Human Resources Issues in Higher Education Presentation's Focus, 2010). Since talent
A MEASUREMENT MODEL OF TALENT

Miiro Farooq Azam Othman Mohamad Sahari Nordin Mohd Burhan Ibrahim 
A MEASUREMENT

MODEL

OF TALENT

Miiro Farooq

Azam Othman

Mohamad Sahari Nordin

Mohd Burhan Ibrahim management practices aim at warranting right individuals in the right positions within an organisation, university authorities should therefore, endeavour to uphold to its sustainability and norms for preparation of future leadership. This is due to the fact that leadership continuity is a key issue towards individual advancement, and it is therefore always important for a university to have a pool of such individuals to avoid any eventualities that can be brought about by natural factors (Riccio, 2010).

Indeed, when talent management is practiced well, it will provide the job security for staff and at the same time yield positive and significant impact on the university performance at large. For instance, the employee attitudinal outcomes and organizational effectiveness will improve and reduce on challenges such as poor managerial practices and situational factors that normally result into complains of poor quality service, high turnover, absenteeism and stress. Whilst the university should task the academic staff for further training and development both at local and international levels to facilitate exposure and acquisition of experiences from other parts of the world (Choong et al., 2011). Moreover, this will require the support from the leadership towards change through staff behaviour and empowerment to win their commitment towards achievement of increased organization performance (Rudhumbu, 2014; Sarangi, 2013). Since the knowledge society requires competencies of human resources to boost organisational transformation and effective performance, it is imperative on the side of the university administration to maintain and enhance staff development programs (Nijveld, 2014; Meyers, 2014; Collings and Mellahi, 2009).

From the literature review the research problem, and the research framework is developed. The study seeks to examine the underlying structure of talent management construct as perceived by university staff in Uganda, which consist of talent identification, talent development, talent culture and retention. Since there is no agreed upon theory on the measurement construct of talent management, the current study is geared towards expanding the efforts of the conceptual frameworks done by Chambers, Foulton, Handfield-Jones, Hankin, and Michaels III, (1998); A. M. Oehley (2007); Beechler and Woodward (2009); Cannon and Mcgee (2011); Guthridge et al., (2008); Oladapo, (2014); Annakis et al., (2014).

\subsection{Statement of the problem}

Many organisations attach a lot of importance to increasing talent-strategy practices to meet the standards of the competitive and dynamic market (Tymon et al., 2010; Vaiman, 2010; Schuler et al., 2011; Scullion et al., 2010; Tarique and Schuler, 2010). However, educational institutions in some parts of the world still lag behind, for instance, universities still face mega challenges in terms of maintaining talented staff especially in Uganda for example, suitable human resources are hard to nurture and locate, but can easily dissipate to other parts 
of the world causing a surplus in those areas and a shortage locally (Mayer et al., 2014; Collings, 2011). Furthermore, there is scarcity in the bracket of the young people and abundance in that of aged groups (Barkhuizen et al., 2014; Wilska, 2014). High competition for innovative skills and brain drain exist (Iqbal et al., 2013; Annakis et al., 2014; Zeelen, 2012). Such challenges as mentioned above are normally realised in university graduates inefficiency and inadequacy in terms of the knowledge, skills and qualities acquired from the universities visa-vi the market demands and employers' prospective. Hence, this study was undertaken in 2016 to illustrate the gap in the literature by exploring the talent management practices among universities in the central region of Uganda. The paper intended to unpack the relationships between talent management dimensions, as perceived by university staff. This study seeks to expand our understanding of talent management practices by extending it to university level where staff perceptions were examined.

\subsection{Research questions}

In order to address and examine the multidimensionality of the talent management construct we formulated the following research questions:

1) What is the underlying structure of talent management construct as reported by Ugandan university staff?

2) How sound are the psychometric properties of the measure of staffs' perceptions on talent management - with regard to convergent validity, discriminant validity and reliability? and

3) Is the measurement model suitable for the measurement of talent management across working experience and gender?

\section{Hypotheses}

$\mathrm{H}_{1}$ : University Staffs' perception towards talent management practices contain four main interconnected factors, which are talent identification, talent development, talent culture and retention.

$\mathrm{H}_{2}$ : The four-factor talent management survey is psychometrically sound with regard to reliability, convergent validity, and discriminant validity.

\section{Method}

\subsection{Sample}

The study sample comprised 808 fulltime academic and administrative staff from six (6) public and private universities in the central region of Uganda. Stratified random sampling procedure was employed in the study. With easy accessibility to the respondents, the 2000 questionnaires were circulated to the targeted staff across the six universities. 847 filled research surveys were 
A MEASUREMENT

MODEL

OF TALENT

Miiro Farooq

Azam Othman

Mohamad Sahari Nordin

Mohd Burhan Ibrahim given back directly to the researchers by research assistants. However, only 808 filled questionnaires met the requirements after scrutiny. The sample size was acceptable to address the study's research questions with the help of structural equation modelling which requires a big number of sample. The big sample was also appropriate in meeting the conditions for using a confirmatory factor analysis (CFA) (Kline, 2011; Hooper et al., 2008; Jayasinghe-Mudalige et al., Udugama and Ikram, 2012; Mann and Mann, 2011).

\subsection{Measurement}

For data collection process, the study administered a 24-item questionnaire to measure university staff's perception towards talent management practices. The survey framework which comprises of three main sections was developed from the previous studies after thorough literature review, for instance (Annakis et al., 2014; Oehley, 2013). The content validity of questionnaire items was done by experts before being commissioned for this study. The collation of the items in the survey tool was in line with the expectation of four sub-constructs indicators of measuring talent management practices, namely talent identification (7 items), talent development ( 5 items), talent culture (5 items), talent retention (5 items). The first section of the survey contained screening questions which allowed the investigators to identify respondents demographic factors; the second section of the survey illustrated the talent management practices variables that were verified in the survey with a Likert scale of five points ranging from: 'strongly disagree"'(1) to 'strongly agree"'(5). The Cronbach's Alpha indices was comfortably above the threshold of $(\alpha>$.70), hence meeting the requirement of validity.

\subsection{Procedure for Data Analysis}

First of all, the study tested the dimensions of the model for talent management practices and this was done to verify the suitability of the hypothesized measurement model through the use of confirmatory factor analysis. The anticipated multidimensionality of talent management construct showed that the four-factor measurement model yielded better fit, without undermining the credibility of a multidimensional talent management questionnaire (Jackson et al., 2009; Bollen, 1986; Siddiqui et al., 2015). Later, the process of addressing the subject of common method bias was undertaken, and an apparent consequence of employing a solitary survey tool to gather and examine university staff's perception data of what is supposed to be independent, albeit connected constructs was revealed (Meade et al., 2007; Podsakoff et al., 2011). After conducting data analysis of the study, hypothesis testing was done through a use of several statistical tools and methods encompassed in SPSS software version 22, to attain Descriptive statistics features such as (frequency, 
means, standard deviations, reliability, and inter correlations). Meanwhile, to achieve the objective of testing the hypothesis of Confirmatory Factor Analysis (CFA). AMOSv.22 was also employed to realize analyses of the goodness of the fit for the measurement model. The measurement model was assessed basing on the covariance matrix ensuing from the data. The likelihood assessment maximum procedure was implemented to produce estimates of defendable properties. The assumption of univariate normality proved acceptable after running the Initial analysis (Byrne, 2010; Kline, 2011). Additionally, the model adequacy was evaluated by means of the extensively known standards for a good-fit CFA, which include: (i) uniformity of the measurement model with the data, and (ii) rationality in the parameter estimates. Data analysis further employed fit indexes that include CFI (Comparative Fit Index), RMSEA (Root Mean Square Error of Approximation) and the relative Chi-square $(\chi 2 / \mathrm{df})$. Arbuckle and Wothke (1995) recommend that value of between 2 and 5 is the measurement acceptable for the CMIN/df, while a value of one (1) or near to (1) demonstrates a good fit for CFI. Lastly, a value 0.06 or less shows a rational error of estimation of RMSEA. Furthermore, the psychometric properties of the model of study were scrutinized the by evaluating the components of construct validity, which are convergent validity and discriminant validity. An examination was further done on internal consistency of each sub-construct through the use

of composite reliability and Cronbach's alpha. Lastly, to test the moderation effect of both working experience and gender a multigroup analyses were done to determine gender variance and working experience invariance of the talent management questionnaire. A two-step simultaneous analysis on both the male (n1=473) and female (n2=347) and working experience groups was conducted, to establish both the gender variance and working experience-invariant measure. This was done through the use un-constraining the factor loadings, intercepts and residual errors; the results derived a baseline Chi-square value. Second, all loadings, intercepts the residual errors were constrained to be equal in the two samples (Wu et al., 2007).

\section{Results}

The table illustrates the descriptive statistics of the items encompassed in the in talent management questionnaire on which the confirmatory analysis was done. The reliability of items scores for each subdimensions of talent management construct ranged between $0.07-0.06$ since it is the extreme possible score; and the mean score was distributed among all items and the results were in tandem with the hypothetical mean of 2.5. The value of each Cronbach's alpha, was reasonably high thus, meeting the internal consistency index of the responses to the related items. For reliability index, the minimum value was .79 therefore, the critical cut score of .70 was exceeded the for a reliable measure. 
A MEASUREMENT

MODEL

OF TALENT

Miiro Farooq

Azam Othman

Mohamad Sahari Nordin

Mohd Burhan Ibrahim

Table 1

\begin{tabular}{|c|c|c|c|c|}
\hline Code & Dimension & Mean & SD & Alpha \\
\hline & Talent identification & & & .836 \\
\hline id2 & $\begin{array}{l}\text { The university makes use of the available assessment tools to } \\
\text { scrutinize new recruits to work }\end{array}$ & 3.37 & 1.110 & \\
\hline id3 & $\begin{array}{l}\text { Human resource manager addresses my performance in a time- } \\
\text { ly way without letting poor performance continue }\end{array}$ & 3.30 & 1.134 & \\
\hline id4 & $\begin{array}{l}\text { University leadership adjust managerial decisions and actions } \\
\text { to be appropriate with my performance }\end{array}$ & 3.35 & 1.091 & \\
\hline id5 & $\begin{array}{l}\text { My university leadership is aware of my performance level and } \\
\text { ability towards transformation }\end{array}$ & 3.53 & 1.084 & \\
\hline \multirow[t]{2}{*}{$1 \mathrm{d6}$} & $\begin{array}{l}\text { The university is always on the lookout for talent people to } \\
\text { occupy important positions }\end{array}$ & 3.47 & 1.152 & \\
\hline & Talent development & & & .757 \\
\hline Td2 & $\begin{array}{l}\text { The university management motivates me with updated feed- } \\
\text { back for my career developmental purposes }\end{array}$ & 3.27 & 1.160 & \\
\hline Td4 & $\begin{array}{l}\text { My university leadership assessed my individual career deve- } \\
\text { lopment needs }\end{array}$ & 3.40 & 1.136 & \\
\hline \multirow[t]{2}{*}{ Td5 } & $\begin{array}{l}\text { University leadership possesses a genuine interest to foster my } \\
\text { learning and career development }\end{array}$ & 3.42 & 1.161 & \\
\hline & Talent culture & & & .788 \\
\hline c1 & $\begin{array}{l}\text { My colleagues and I have been rewarded by my university for } \\
\text { being exemplary at work }\end{array}$ & 3.31 & 1.246 & \\
\hline c3 & $\begin{array}{l}\text { I have been given salary increment in accordance to level of } \\
\text { career development and performance }\end{array}$ & 3.26 & 1.226 & \\
\hline \multirow[t]{2}{*}{ c4 } & My university ensures, that salaries are market related & 3.23 & 1.172 & \\
\hline & Talent retention & & & .785 \\
\hline r1 & $\begin{array}{l}\text { The university provided me with standardized job description } \\
\text { and performance requirements to avoid boredom }\end{array}$ & 3.47 & 1.148 & \\
\hline r2 & $\begin{array}{l}\text { I have been motivated by the university leadership through use } \\
\text { of the resources available, time \& materials }\end{array}$ & 3.50 & 1.156 & \\
\hline r3 & $\begin{array}{l}\text { The university leadership communicates to staff the university } \\
\text { common goal and agenda }\end{array}$ & 3.47 & 1.139 & \\
\hline
\end{tabular}

\subsection{Validity of talent management multidimensions}

A confirmatory factor analysis (CFA) was done on the obtained data to achieve the validity of the construct talent management survey. The findings of the study showed that the score for factor loadings of items for the subdimensions of talent management construct were above the minimum threshold value 0.5 . This was symbolic that the results have met the required estimates(Byrne, 2009; JayasingheMudalige et al., 2012; Kline, 2011; Livote, 2009; Mann and Mann, 2011; 


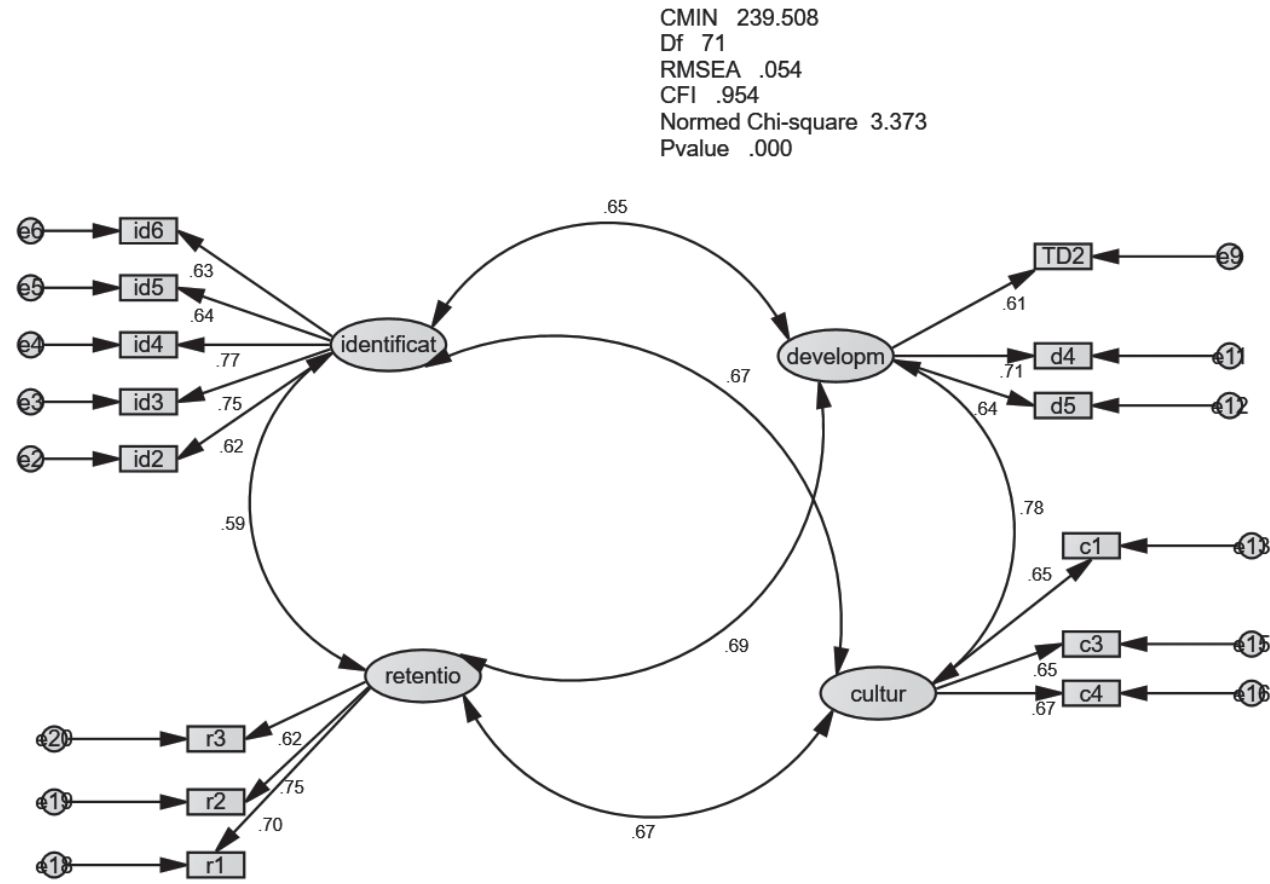

CMIN 239.508

RMSEA 054

CFI .954

Pvalue .000

Westen and Rosenthal, 2003). Also the results of the CFA tested a four- factor hypothesized measurement model with four dimensions of talent management practices. The obtained results from the data of the study reflected model fitness in terms the variance-covariance matrix whereby $\mathrm{CMIN} / \mathrm{df}=4.031, \mathrm{RMSEA}=.061$, Pvalue $=.000, \mathrm{CFI}=.904, \mathrm{df}=203$ and $\mathrm{CMIN}=818.390$. Furthermore, the parameter estimates were considerably significant statistically. The factor loadings magnitude and directions acted as expected as indicated in the Figure below.

\subsection{Psychometric Properties of Talent Management Questionnaire}

The study findings provided evidence that back the psychometric properties of the talent management tool in terms of its convergent validity and discriminant validity (Table 2). Since most of the values of the AVE of the constructs were larger than the threshold of 0.5 , there is evidence of convergent validity. In addition, the measure of talent management adequately satisfied discriminant validity as most of the AVEs were larger than the values of the corresponding shared variances (values above the diagonal). Moreover, the moderation between inter-factor correlations showed that Talent management was a multidimensional construct containing distinct but inter-related dimensions. Lastly, the composite reliability of each construct ranged between .505 (culture) and .814 (identification) was indicated by the data.
A MEASUREMENT MODEL OF TALENT

Miiro Farooq Azam Othman

Mohamad Sahari Nordin

Mohd Burhan Ibrahim

Figure 1.

Talent management construct measurement model 
A MEASUREMENT

MODEL

OF TALENT

Miiro Farooq

Azam Othman

Mohamad Sahari Nordin

Mohd Burhan Ibrahim

Table 2.

\begin{tabular}{lrrrr}
\hline Dimension/construct & $\mathbf{1}$ & $\mathbf{2}$ & $\mathbf{3}$ & $\mathbf{4}$ \\
\hline Identification & .50 & .422 & .449 & .348 \\
\hline Development & .65 & .428 & .608 & .480 \\
\hline Culture & .67 & .78 & .431 & .449 \\
\hline Retention & .59 & .69 & .67 & .50 \\
\hline Composite Reliability & .814 & .691 & .505 & .736 \\
\hline
\end{tabular}

$N B$. The diagonally shown values above are the average variance extracted (AVEs) for individual sub-dimension; and under the diagonal is the correlation matrix; whereas, the shared variance matrix is above the diagonal.

\subsection{The gender and working experience-invariant of Talent management}

Research question three of this study aimed at assessing the factorial invariance of Talent management beyond gender and working experience. The Chi-square value produced by the constrained measurement model was evaluated against the baseline value for statistically significant differences.

Table 3.

\begin{tabular}{|c|c|c|c|c|c|c|}
\hline Variables & Mode & $\chi^{2}$ & df & $\begin{array}{l}\text { Critical } \\
\text { value }\end{array}$ & $\begin{array}{l}\text { Result on } \\
\text { moderation }\end{array}$ & Results \\
\hline \multirow[t]{3}{*}{ Gender } & Unconstrained & 1146.022 & 406 & & Not significant & Supported \\
\hline & Constrained & 1162.769 & 424 & & & \\
\hline & Change & 16.747 & 18 & 28.87 & & \\
\hline \multirow[t]{3}{*}{$\begin{array}{l}\text { Working } \\
\text { Experience }\end{array}$} & Unconstrained & 2556.502 & 1231 & & Significant & $\begin{array}{l}\text { Not suppor- } \\
\text { ted }\end{array}$ \\
\hline & Constrained & 2592.302 & 1249 & & & \\
\hline & Change & 35.8 & 18 & 28.87 & & \\
\hline
\end{tabular}

The invariance test across the female and male groups resulted into a statistically insignificant change in the Chi-square value, Chi-square $(\mathrm{df}=18)=$ 16.747 (Table 3). Whereas the invariance assessment beyond working experience resulted in a statistically significant change in the Chi-square value, Chi-square $(\mathrm{df}=18)=35.8$. Thus, the measurement model is gender-invariant but working experience variant.

\subsection{Discussion}

The study findings are in support of the previous reach results on talent management practices and have further illuminated on the concept of talent management in numerous ways. First of all, from the results of this study, 
a measurement model was generated, additional evidence about talent management as a multidimensional construct has been provided. This is especially true because the covariance matrix was consistent with the data. In totality, the results from CFA proffer evidence that is in support of the multifactor nature of university staff's perception on talent management practices among universities in central region of Uganda. The talent management construct is composed of four dimensions, namely identification, development, culture, and retention. Therefore, it is defensible to employ the four-multidimension questionnaire to systematically measure staff perceptions of talent management practices while managing universities in Uganda. The four-factor structure model effectively signified the observed data (Annakis et al., 2014; Iqbal et al., 2013). The dimensions of talent management construct are still in line with the prevailing talent management framework as proposed in previous researches (Oehley, 2007; Chambers et al., 1998; Cannon and McGee, 2011; Beechler and Woodward, 2009; Guthridge et al., 2008; Oladapo, 2014; Lövebrant and Emelie, 2012; Practices, 2012; Smith, 2012; Chambers et al., 1998). Unlike (Annakis et al., 2014; Cipd, 2008; Bradley, 2016) whose work focused on universities talent management practices in some other parts of the world, the focus of current study was on talent management practices as a duty of each of individual university, thus involving only known four components of talent management structure (Annakis et al., 2014; Oehley, 2007).

The subsequent research question of the study was to measure the validity and reliability of the talent management construct practices. The result showed sufficient levels of internal consistency for each dimension. Thus, the study results indicated the indexes for reliability ranged between $\alpha=.505$ (talent culture) and $\alpha=.841$ (talent identification). Furthermore, the study data presented was also buttressed by the convergent validity and discriminant validity of talent management practices. The AVE of most of the construct dimensions surpassed the verge of importance and moderated the inter-correlations amid the subconstructs of talent management. The recent study also demonstrated that the 15-items of survey was proper in measuring university staff' answers to talent management practices. It is therefore sensible to deduce that the questionnaire satisfactorily explained the importance and variability of a four subconstruct of talent management practices among Universities in the central region of Uganda.

In addition, the study findings proved the validity of responses across gender and working experience. The findings of numerous group CFA reflected that measurement of talent management practices systematically did not vary amongst females and males. Meanwhile, those for working experience varied systematically between the groups. From the results for gender invariance we learn that the talent management construct is configurable and valid metrically on the foundation of the outcomes of stringent invariant investigation measure 
A MEASUREMENT

MODEL

OF TALENT

Miiro Farooq

Azam Othman

Mohamad Sahari Nordin

Mohd Burhan Ibrahim on gender which did not vary significantly. Thus, it is rational then to arrive on the conclusion that the demographic variable of gender had no moderation effect since it did not relate with any of the fundamental influential subconstructs on university staffs' responses towards talent management questionnaire. Meanwhile the study had proved with evidence that working experience has a strong variance of the questionnaire. Whereby, working experience results revealed that that talent management multidimension are not configurable and metrically valid since the results are statically significant across the groups. The study outcomes suggest that the dimension of talent management is not pertinent to either groups, especially in other parts of the world like central region of Uganda.

\section{Conclusion and Recommendations}

There are several pertinent issues in conclusion for educational manager, administrator and practitioners at university levels. First of all, talent management practices ought to be examined and expose staff such that this mentality sinks into workers at all levels to exhibit excellent and effective performance. The model further suggests that the four main practices in talent management that clearly influence staff performance and effectiveness at work. The main results from a confirmatory factor analysis of talent management are indeed proposed to be used at universities in order to get better understanding of employee needs against institutional development.

Secondly, retention of staff can be achieved through support of professional development and this should be done in conformity with the university strategy. It is critical to align it clearly with most especially the situation at hand. This is because many universities have shortages in ensuring that such alignment helps staff perform to the expectations. lastly, institutionalization of talent management practices can bring about satisfaction in universities and enhance better understanding and productivity among the staff and their managers. This can be mirrored in the energy each of the employees' performance beyond gender and working experience to better institutional performance. Thus, resulting into better competition that can lead to coping up with the global market place.

Nevertheless, the study results were limited in some important areas. To begin with, the whole spectrum of universities in the central region of Uganda was not covered, due to several reasons for instance strikes and closure of some institutions. The validated questionnaire may become outdated in some aspects of talent management practices as time goes by, the validated. This is due to rapidness of change for example, it may be found that in future some items in some dimensions are irrelevant as new knowledge and discoveries may add some other features to the practices since there is no agreed upon theory as at this moment. Thus, warranting regular content-validation of talent management practices questionnaire. Additionally, the study sample was homogenous in nature due to 
the fact that a group of university staff employed in the study were employees of both public and private universities in Uganda. The results of future researchers on the same subject may differ due to different populations backgrounds and cultures. Future studies involving varied university staff both within and outside the country samples may suggest valuable perceptions on the comparability of the instrument across age group and culture.

In conclusion, further apprehension about the meaning and nature of staff's perception towards talent management practices has been imparted by this study. The study data has greater useful information on the ongoing attempts in planning and development of universities towards meeting the global demands through the use of talent management practices among the university staff. Such efforts are defensible to help universities to enhance proper recruitment, development, and retain the talent staff towards achievement of university mission.

\section{References}

Aljunaibi, M. M. (2014), “Talent Management and Employee Engagement”, Disertations, The British University in Dubai, pp. 1-79.

Annakis, D., Dass, M., Isa, A. (2014), "Exploring Factors that Influence Talent Management Competency of Academics in Malaysian GLC's and Non-Government Universities", Journal of International Business and Economics (Online) Journal of International Business and Economics, Vol. 2 No. 24, pp. 163-185. DOI: https://doi. org/10.15640/jibe.v2n4a9

Ariss, A. Al. (2014), "Global Talent Management: An Introduction and a Rewiev", Global Talent Management, Vol. 126, pp. 3-13. DOI: https://doi.org/10.1007/978-3-319-0 5125-3

Barkhuizen, N., Mogwere, P., Schutte, N. (2014), “Talent Management, Work Engagement and Service Quality Orientation of Support Staff in a Higher Education Institution", Mediterranean Journal of Social Sciences, Vol. 5 No. 4, pp. 69-77. DOI: https://doi. org/10.5901/mjss.2014.v5n4p69

Barkhuizen, N., Welby-cooke, G., Schutte, N., Stanz, K. (2014), "Talent Management and Leadership Reciprocity: The case of the South African Aviation Industry", Mediterranean Journal of Social Sciences, Vol. 5 No. 9, pp. 11-17. DOI: https://doi. org/10.5901/mjss.2014.v5n9p11

Bauer, M., Greven, F. (2015), "Talent Management in a Different Light A practice-based case study on an MNC", Master Degree Project in Management, University of Gothenburg, Sweden.

Beechler, S., Woodward, I. C. (2009), “The global "war for talent”, Journal of International Management, Vol. 15 No. 3, pp. 273-285. DOI: https://doi.org/10.1016/j. intman.2009.01.002

Bethke-Langenegger, P., Mahaler, B. S. (2011), "Effectiveness of Talent Management Strategies", European J. International Management, Vol. 5 No. 5, pp. 524-539. DOI: https://doi.org/10.1504/EJIM.2011.042177 
A MEASUREMENT

MODEL

OF TALENT

Miiro Farooq

Azam Othman

Mohamad Sahari Nordin

Mohd Burhan Ibrahim
Bollen, K. A. (1986), "Sample Size and Bentler and Bonnets Nonnormal Fit Index", The Psychometric Society, Vol. 1, pp. 375-377.

Bradley, A. P. (2016), “Talent management for universities", Australian Universities' Review, Vol. 58 No. 1, pp. 13-19.

Campbell, V., Hirsh, W. (2013), “Talent Management: A Four-Step Approach”, Institute for Employment Studies, Raport 502, pp. 1-54.

Cannon, J. A., Mcgee, R. (2011), Talent management and succession planning, Chartered Institute of Personnel and Development, London.

Chambers, E. G., Foulton, M., Handfield-Jones, H., Hankin, S. M., Michaels III, E. G. (1998), “The war for talent”, McKinsey Quarterly, Vol. 3, pp. 44-57. DOI: https:// doi.org/10.1080/03071840308446873

Cipd, (2008), "Leading HR for high performance in higher education", available at: http:// www2.cipd.co.uk/NR/rdonlyres/4AD775C1-3621-4D8B-9262-0DE659C9395D/0/ leading_hr_performance_higher_education.pdf (accessed 11 January 2017).

Collings, D. G. (2014), "Integrating global mobility and global talent management: Exploring the challenges and strategic opportunities", Journal of World Business, Vol. 49 No. 2, pp. 253-261. DOI: https://doi.org/10.1016/j.jwb.2013.11.009

Collings, D. G., Mellahi, K. (2009), "Strategic talent management: A review and research agenda", Human Resource Management Review, Vol. 19 No. 4, pp. 304-313. DOI: https://doi.org/10.1016/j.hrmr.2009.04.001

Commission, B., Sustainable, I., America, N. (2011), "Leading Sustainable Talent Development in Higher Education, available at: http:/www.chairacademy.com/ conference/2013/_papers/Leading\%20sustainable\%20talent.pdf (accessed 11 January 2017).

Deloitte, (2016), "Global human capital trends 2016. Deloitte University Press", available at: https://doi.org/http://www2.deloitte.com/us/en/pages/human-capital/articles/ employee-engagement-culture-human-capital-trends-2015.html (accessed 11 January 2017).

Devins, D., Gold, J. (2014), "Human Resource Development International Re-conceptualising talent management and development within the context of the low paid", Human Resource Development International, Vol. 17 No. 5, pp. 514-528. DOI: https://doi. org/10.1080/13678868.2014.954191

Gakure, R. W., Kamau, A. W., Waititu, A. G. (2013), "Reward Systems as Determinant Of Talent Management in Public Universities in Kenyaln", IOSR Journal Of Humanities And Social Science (IOSR-JHSS), Vol. 18 No. 2, pp. 41-47.

Guthridge, M., Komm, A. B., Lawson, E. (2008), "Making talent a strategic priority", McKinsey Quarterly, available at: http://www.americasdiversityleader.com/Downloads/McKinsey\%20Report,\%202008.pdf (accessed 11 January 2017).

Hooper, D., Coughlan, J., Mullen, M. (2008), “Structural Equation Modelling : Guidelines for Determining Model Fit Structural equation modelling: guidelines for determining model fit", Electronic Journal of Business Research Methods, Vol. 6 No. 1, pp. 53-60.

Iqbal, S., Qureshi, T. M., Khan, M. A., Hijazi, S. T. (2013), "Talent management is not an old wine in a new bottle", African Journal of Business Management, Vol. 7 No. 35, pp. 3609-3619. DOI: https://doi.org/10.5897/AJBM11.855

Jackson, D. D. L., Gillaspy, J. A., Purc-Stephenson, R. (2009), "Reporting practices in 
confirmatory factor analysis: an overview and some recommendations", Psychological Methods, Vol. 14 No. 1, pp. 6-23. DOI: http://dx.doi.org/10.1037/a0014694

Jayasinghe-Mudalige, U. K., Udugama, J. M. M., Ikram, S. M. M. (2012), "Use of Structural Equation Modeling Techniques to Overcome the Empirical Issues Associated With Quantification of Attitudes and Perceptions", Sri Lankan Journal of Applied Statistics, Vol. 13, pp. 15-37.

Keçecioğlu, T., Kemal YILMAZ, M., Büyükşehir Belediyesi, İ., Kelimeler, A., Yönetimi, Y., Sermayesi, İ. (2014), "An Application on the Brand of Talent Management Perspective YeteneYönetimiPerspektifindenBir Marka Uygulamasi”, Journal of Yasar University, Vol. 9 No. 935, pp. 6099-6260.

Kline, R. B. (2011), Principles and Practices of Structural Eqaution Modeling, The Guilford Press New York London, New York.

Knight, M. (2012), "Changing times in UK universities: what difference can HR make?", The Guardian, available at: https://www.theguardian.com/higher-education-network/ blog/2012/may/17/human-resources-in-higher-education (accessed 11 January 2017).

Lövebrant, E. K. R. G. (2012), Banking on Talent, University of Gothernburg, available at: https://www.talentqgroup.com/media/40483/whitepaper-banking-on-talent.pdf (accessed 11 January 2017).

Maphota, M. H. (2016), The state's capacitation of scool principals “ A postivist reflection on the effectiveness of development pragrammes in Soshanguve secondary school, Gauteng Province, University of South Africa, Pretoria, Republic of South Africa.

Mary, O. E., Enyinna, U. K., Ezinne, K. M. (2015), “The Relationship Between Talent Management and Employees Performance in Nigerian Public Sector", International Journal of Economics, Commerce and Management, Vol. 3 No. 5, pp. 1581-1592.

Mayer, P., Wilde, M., Dinku, A., Fedrowitz, J., Shitemi, N. L., Wahlers, M., Ziegele, F. (2014), "Challenges for faculty management at African higher education institution", International Journal of Educational Research, available at: http://www.che.de/ downloads/Challenges_for_faculty_management_at_African_higher_education_institutions_Mayer_et_al_2011.pdf (accessed 11 January 2017).

Meade, A. W., Watson, A. M., Kroustalis, C. M. (2007), “Assessing Common Methods Bias in Organizational Research", 22 nd ANnual Meeting of the Society for Industrial and Organizational Psychology, New York, pp. 1-10.

Meyers, M. C. (2016), "Talent management Towards a more inclusive understanding", Tijdschrift voon HRM, Vol. 12, pp. 1-12.

Moayedi, Z., Vaseghi, M. (2016), "The Effect of Talent Management on Organizational Success", Scinzer Journal of Accounting and Management, Vol. 2 No. 3, pp. 16-20. DOI: https://doi.org/10.21634/SJAM.2.3.1620

Montanini, M. (2013), "Supporting tertiary education , enhancing economic development. Strategies for effective in Sub-Saharan Africa", ISPI Working Paper, Vol. 49, pp. 1-39.

Oehley, A. M. (2007), The Deevelopment and Evaluation of a Partial Talent management Competency Model, Stellenbosch University, Stellenbosch, Republic of Africa.

Oehley, A. M. (2013), "The Development and Evaluation of a Partial Talent Management Competency Model", Journal of Chemical Information and Modeling, Vol. 53, pp. 1689-1699. DOI: https://doi.org/10.1017/CBO9781107415324.004

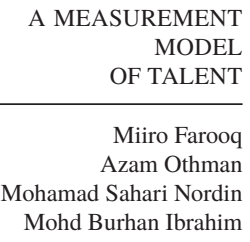

Mohd Burhan Ibrahim 
A MEASUREMENT

MODEL

OF TALENT

Miiro Farooq

Azam Othman

Mohamad Sahari Nordin

Mohd Burhan Ibrahim
Oladapo, V. (2014), “The Impact of Talent Management”, Journal of Business Studies Quarterly, Vol. 5 No. 3, pp. 20-36.

Podsakoff, P. M., MacKenzie, S. B., Podsakoff, N. P. (2011), "Sources of method bias in social science research and recommendations on how to control it", Annual Review of Psychology, Vol. 63 No. 1, pp. 539-569. https://doi.org/10.1146/annurevpsych-120710-100452

Riccio, S. J. (2010), Talent Management in Higher Education: Indetifying and Developing Emerging Leaders Within The Administration at Private Colleges and Universities, Dissertation, University of Nebraska - Lincoln, pp. 1-200.

Richards, Z. (2012), "Conceptions of Academic Talent: Perspectives in Higher Education”, Salzburgh Global Seminar, (2-7 October 2012), Salzburg, Austria.

Rudhumbu, N. (2014), "Implementation of Talent Management Strategies in Higher Education : Evidence from Botswana", International Journal of Higher Education Management, Vol. 1 No. 1, pp. 86-99.

Siddiqui, K. A., Mirani, M. A., Fahim, S. M. (2015), "Model generation using structural equation modeling", Journal of Scientific Research and Development, Vol. 2 No. 10, pp. 112-116.

Sirkova, M., Ali Taha, V., Ferencova, M. (2015), “Talent management: Focus on Slovak enterprises", Economic Annals-XXI, Vol. 1-2 No. 1, pp. 40-43.

Smith, M. (2012), "Beyond hiring : An integrated approach to talent management", McKinsey \& Company, available at: www.mckinsey.com (accessed 11 January 2017).

Stanley, G. (2006), "Seven Principles for Change Management", Sustainable Leadership in Education, (September), pp. 1-10.

Strategic Human Resources Issues in Higher Education Presentation's Focus (2010), available at: http://www.txhehra.org/downloads/CUPAIssues.pdf (accessed 11 January 2017).

Tansley, C., Kirk, S., Tietze, S. (2013), "The currency of talent management-A reply to "talent management and the relevance of context: Towards a pluralistic approach", Human Resource Management Review, Vol. 23 No. 4, pp. 337-340. DOI: https://doi. org/10.1016/j.hrmr.2013.08.004

Tarique, I., Schuler, R. (2012), “Global Talent Management Literature Review”, Fundation Shaping the future of $H R$, available at: https://pl.scribd.com/document/237612023/ Global-Tm-Lit-Review-final (accessed 11 January 2017).

The University of Scranton Planning Office (2009), "College \& university staffing and human resources support trends", available at: http://www.scranton.edu/pir/planning/ Scans and reports/Microsoft Word - HR Staffing Trends_2008.pdf (accessed 11 January 2017).

Vnoučková, L. (2016), "Practices of talent management in organisations in the Czech Republic", Acta Universitatis Agriculturae et Silviculturae Mendelianae Brunensis, Vol. 64 No. 2, pp. 701-709. DOI: https://doi.org/10.11118/actaun201664020701

Wilska, E. (2014), "Determinants of Effective Talent Management", Journal of Positive Management, Vol. 5 No. 4, pp. 77-88. DOI: https://doi.org/10.12775/JPM.2014.025

Wu, A. D., Li, Z., Zumbo, B. D. (2007), "Decoding the meaning of factorial invariance and updating the practice of multi-group confirmatory factor analysis: A demonstration 
with TIMSS data", Practical Assessment, Research \& Evaluation, Vol. 12 No. 3, pp. $1-26$.

Zeelen, J. (2012), "Universities in Africa: Working on Excellence for Whom? Reflections on Teaching, Research, and Outreach Activities at African Universities", International Journal of Higher Education, Vol. 1 No. 2, pp. 157-165. DOI: https://doi.org/10.5430/ ijhe.v1n2p157

Zurich, R. U. L. I. B. (2012), Global TM Lit Review-FINAL, Zurich. 